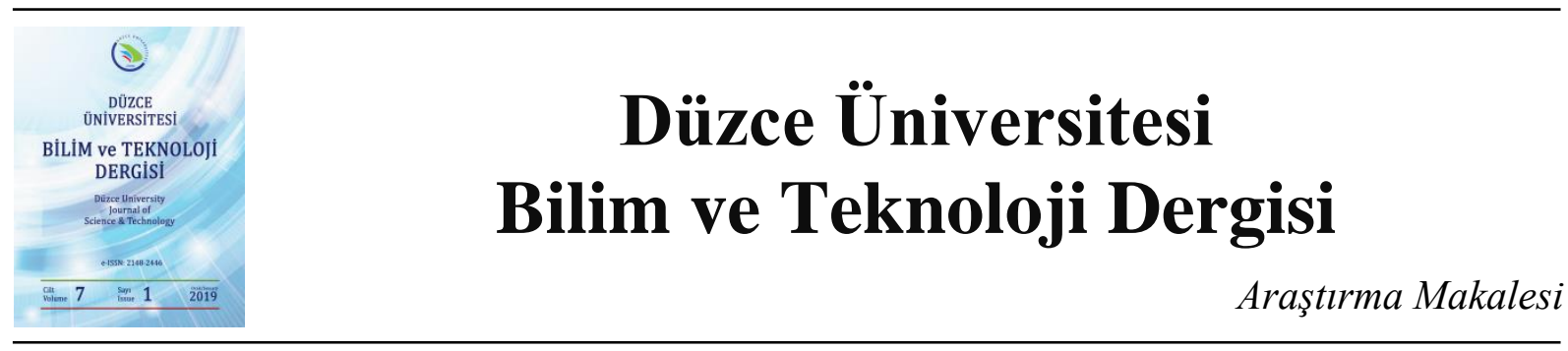

\section{Waspaloy Süper Alaşımının Frezelenmesinde Nanopartikül Katkılı Yağlamanın Takım Aşınması Üzerindeki Etkisinin Araştırılması}

\author{
Çağrı Vakkas YILDIRIM ${ }^{\mathrm{a}}$, Şenol ŞiRìiN ${ }^{\mathrm{b}, *}$, Turgay KIVAK ${ }^{\mathrm{c}}$, \\ ${ }^{a}$ Uçak Gövde-Motor Bölümü, Havacllı ve Uzay Bilimleri Fakültesi, Erciyes Üniversitesi, Kayseri, TÜRKiYE \\ ${ }^{b}$ Makine ve Metal Teknolojileri Bölümü, Gümüşova MYO, Düzce Üniversitesi, Düzce, TÜRKIYE \\ ${ }^{c}$ Imalat Mühendisliği Bölümü, Teknoloji Fakültesi Düzce Üniversitesi, Düzce, TÜRKIYE \\ * Sorumlu yazarin e-posta adresi: senolsirin@duzce.edu.tr
}

\begin{abstract}
ÖZET
Waspaloy gibi işlenebilirliği zor malzemelerin işleme verimliliğini artırmak için, kesme sıvısı kullanımı büyük önem taşımaktadır. Ancak, aşırı kesme sıvısı kullanımı çevre, çalışan sağlığı ve üretim maliyeti gibi konularda imalatçıları endişelendirmektedir. Bu endişeleri minimuma indirmek için kullanılan alternatif yöntemlerden birisi de Minimum Miktarda Yağlama (MMY) sistemidir. Bununla beraber, kesme sıvısı miktarının azaltılması için çalışmalar artarak devam etmektedir. Bu çalışmada, MMY sisteminde kullanılan kesme sıvısının içerisine nanopartikül katkı maddesi eklenerek kullanılan kesme sıvısı miktarını daha da azaltmak amaçlanmıştır. Bu amaç doğrultusunda, Waspaloy süper alaşımı; kuru, MMY ve NanoMMY (hacimce $\% 1 \mathrm{Al}_{2} \mathrm{O}_{3}$ ) şartları altında işlenmiş ve soğutma/yağlama yöntemleri arasındaki farklar ortaya konulmuştur. Frezeleme deneyleri esnasında çıktı olarak takım aşınması seçilmiştir. Kesme parametresi olarak ise üç farklı kesme hızı (20, 40, $60 \mathrm{~m} / \mathrm{dak})$ ve üç farklı ilerleme hızı $(0,05-0,10$ ve $0,15 \mathrm{~mm} / \mathrm{dev})$ seçilmiştir. Deney sonuçlarının analizine göre, optimum aşınma değeri $20 \mathrm{~m} / \mathrm{dak}$ kesme hızı, $0,05 \mathrm{~mm} / \mathrm{dev}$ ilerleme ve NanoMMY şartları altında gerçekleşmiştir.
\end{abstract}

Anahtar Kelimeler: Waspaloy, Takım aşınması, NanoMMY

\section{Investigation of the Effect on Tool Wear of Nanoparticle Added Lubrication in Milling of Waspaloy Super Alloy}

\begin{abstract}
The use of cutting fluids is of great importance in order to increase the machinability efficiency of difficult-tocut materials such as Waspaloy. However, the use of extreme cutting fluid is concerned by manufacturers in such issues as the environment, human health and production cost. One of the alternative methods to minimize these concern is the Minimum Quantity Lubrication (MQL) system. Moreover, researches are continued to reduce the amount of cutting fluids. In this study, it was intended to further reduce the amount of cutting fluid so nanoparticle was added to the contents of the cutting fluid in the MQL system. For this purpose, Waspaloy milling experiment were carried out under dry, MQL and NanoMQL ( 1 vol\% $\left.\mathrm{Al}_{2} \mathrm{O}_{3}\right)$ conditions and the
\end{abstract}


differences between cooling/lubrication methods have been revealed. Tool wear was selected as output parameter during milling experiments. Three different cutting speeds $(20,40,60 \mathrm{~m} / \mathrm{min})$ and three different feed rates $(0.05,0.10$ and $0.15 \mathrm{~mm} / \mathrm{rev})$ were selected as cutting parameters. According to the analysis of the experiment results, the optimum wear value was $20 \mathrm{~m} / \mathrm{min}$ cutting speed, $0.05 \mathrm{~mm} / \mathrm{rev}$ feed rate and NanoMMY cutting conditions.

Keywords: Waspaloy, Tool wear, Nano MQL

\section{GiRIS}

$\mathrm{T}$ alaş kaldırma işlemi, ana üretim yöntemlerinden biridir ve işlemin gerçekleşmesi için genellikle çok yüksek bir enerjiye ihtiyaç vardır. Bu enerji ile gerçekleştirilen bir talaş kaldırma operasyonunda, yüksek sürtünme ve dolayısıyla çok yüksek sıcaklıklar ortaya çıkmaktadır. Sürtünme ve yüksek sıcaklıkların oluşum bölgesi ise kesici takım, iş parçası ve talaş arayüzeyleridir [1]. Sürtünme ve sıcaklık gibi sınırlamalara rağmen imalatçılar, kesme kuvveti, takım ömrü ve yüzey pürüzlülüğü gibi işlenebilirliğin temel parametrelerinin optimumunu yakalamak için yoğun bir çaba sarf etmektedirler. Bu durum özellikle, Waspaloy gibi kompresör ve rotor diskleri, miller, vidalar, bağlantı elemanları, uçak gövdesi, petrokimya ekipmanları, füze sistemleri, çeşitli motor parçaları gibi geniş kullanım alanına sahip ve işlenebilirliği son derece zor malzemeler için daha büyük önem taşımaktadır [2]. Dolayısıyla, kesme bölgesinde oluşan sürtünme ve ısının kontrol altına alınması talaş kaldırma operasyonunun verimliliği için oldukça önem arz etmektedir. Bunun için uygulanan yöntemlerin en başında da kesme sıvısı kullanılan soğutma yöntemleri gelmektedir.

Talaş kaldırma operasyonlarında kesme sıvısı kullanımıyla; takım ömrü, yüzey kalitesi ve boyutsal doğruluk açısından oldukça kayda değer iyileşmeler sağlanabilmektedir. Kesme sıvıları ayrıca, talaşı uzaklaştırma ve talaş kırma gibi görevleri de yerine getirmektedirler [3]. Bu iyileştirmelere karşın, yüksek miktarda kesme sıvısı kullanımı, satın alma, kullanma, depolama, bertaraf etme gibi nedenlerle üretim maliyetlerinin artırmasının yanında, atıkların doğru metotlarla bertaraf edilememesi nedeniyle toprak, su ve çevre kirliliğine neden olabilmektedir. Ayrıca, çalışma ortamındaki havayı kirletmesi, bu kirli havanın çalışan tarafından solunması ve sürekli cilde temas etmesi nedeniyle çok ciddi solunum ve cilt rahatsızlıklarına neden olabilmektedir [1]. Bu olumsuz etkilerinden dolayı imalatçılar ve araştırmacılar kullanılan kesme sıvısı miktarını azaltmak için çeşitli çalışmalar yapmışlardır. $\mathrm{Bu}$ araştırmalar sonunda elde edilen ve kesme sıvısına alternatif yöntemlerden biri de kuruya yakın işleme olarak da tanımlanan Minimum Miktarda Yağlama (MMY) yöntemidir. MMY yöntemi özellikle hafif ve orta seviyedeki talaş kaldırma operasyonlarında önemli iyileştirmeler sağlamaktadır [4]. Dahası, verimlilik, çevre dolayısıyla ekolojik açından önemli iyileştirmeler sunmaktadır. Bununla birlikte, MMY sistemi ile işlemede, talaşı kesme bölgesinden uzaklaştırma gibi bazı temel konularda sınırlamalar ortaya çıkmakta ve bu da dezavantaj olarak verimliliği azaltmaktadır [5]. Talaşı kesme bölgesinden uzaklaştırma gibi sınırlamalar basınçlı hava yardımıyla bir miktar çözülebilir gibi dursa da MMY sisteminin soğutma kapasitesinin konvansiyonel kesme sıvısına göre daha düşük olması bu sistemin endüstriyel uygulamalarda tam kapasite ile çalışmasını engellemektedir [4]. Tüm bu sınırlamaların ana nedeni ise kullanılan kesme sıvısı miktarının çok az olmasıdır. Bir başka deyişle, kesme sıvısı miktarı çok az olduğu için kullanılan kesme sıvısı klasik kesme sıvılarına göre üstün özelliklere sahip olmalıdır. Bu durumda da katı akışkanlar ya da nano akışkanlar denilen ve temel 
prensibini kesme sıvısının içerisine nano boyuttaki katı yağlayıcıların eklendiği yöntem son zamanlarda ön plana çıkmaktadır.

Kesme sıvısına eklenen nanopartiküllerle hazırlanan nanoakışkanlar ya kesme sıvılarının kullanımını ortadan kaldırmak ya da kayganlık ve soğutmayı arttırmak için kullanılmaktadır. Nanoakışkan olarak molibden disülfit $\left(\mathrm{MoS}_{2}\right)$, grafit, bor nitrür $(\mathrm{BN})$ ve politetrafloroetilen (PTFE), $\mathrm{Al}_{2} \mathrm{O}_{3}$ gibi kat1 kayganlaştırıcı katı partiküller tercih edilmektedir [4]. Nanoakışkanların hazırlanmasında, nanopartikül seçimi kritiktir ve uygulamaya bağlı olarak değişiklik göstermektedir. Nanoakışkanların tercih edilmesinin bir başka nedeni ise MMY sisteminde kullanılan mineral veya bitkisel esaslı kesme sıvılarının yağlama özelliklerinin iyi olmasına karşın, soğutma özelliklerinin yeterli olmamasıdır. $\mathrm{Bu}$ durum ise kesme yağlarının termal iletkenliğinin zayıf olması ile açıklanabilir. Termal iletkenliği artırmak için ise katı yağlayıcı da denilen nano yağlayıcılar eklenmektedir. Uygulama durumuna göre seçilen ve yağ partiküllerini tutma konusunda iyi bir kapasiteye sahip olan nano yağlayıcılar, böylelikle kesme bölgesinde oluşan 1sıyı daha kolay kesme bölgesinden transfer edebilmekte ve soğutma adına önemli iyileştirmeler sağlayabilmektedirler. Nanoakışkanlar ile yapılan bazı işlenebilirlik çalışmaları aşağıda sunulmuştur.

Literatürde yer alan çalışmaların bir kısmı bu çalışmada verilmiştir. Daha önce yapılan benzer çalışmalar incelenirse genellikle tornalama, taşlama ve benzeri operasyonlarda uygulandığ görülmektedir. Dahası, yapılan çalışmalar genellikle orta ve hafif işleme koşullarında yapılmış ve ağır işleme koşulları ile ilgili çok az çalışma yapılmıştır. Yapılan bazı çalışmalar sıralanacak olursa, Uysal ve arkadaşları $\mathrm{MoS}_{2}$ nano yağlayıcı ekledikleri MMY sistemini kullanarak AISI 420 çeliğini frezelerken bitkisel kesme sıvısının içine ağırlıkça \%1 oranında $\mathrm{MoS}_{2}$ eklemişler ve nanopartikül katkılı kesme sıvısının, işlenebilirlik üzerindeki etkisini incelemişlerdir. İşlenebilirlik göstergesi olarak takım aşınması ve yüzey pürüzlülügünü seçen araştırmacılar, çalışma sonunda $40 \mathrm{ml} / \mathrm{saat}$ debiye sahip nanopartikül katkılı MMY sisteminin en iyi sonucu verdiğini iddia etmişlerdir [6]. Park ve arkadaşları Ti-6Al-4V titanyum alaşımını frezelemişler ve konvansiyonel işleme, kriyojenik işleme, MMY ile işleme ve NanoMMY ile işlemenin arasındaki farkları incelemişlerdir. Kesme sıvısı olarak ester bazlı bitkisel yağ kullanan araştırmacılar, katkı maddesi olarak hegzagonal Bor Nitrürü (hBN) tercih etmişler ve ağırlıķa \%5 oranında ilave etmişlerdir. Kesme kuvveti ve takım aşınmasını inceleyen araştırmacılar, sonuç olarak NanoMMY ve kriyojenik sistemin ortak kullanımının diğer soğutma yöntemlerine göre daha iyi sonuç verdiğini iddia etmişlerdir [7]. Park ve arkadaşları, AISI 1045 çeliğini frezeleyerek kesme sıvısı uygulama yönteminin takım aşınması üzerindeki etkilerini incelemişlerdir. Soğutma/yağlama yöntemi olarak kuru, MMY ve nanopartikül katkılı MMY sistemini seçen araştırmacılar, katkı malzemesi olarak da nano grafeni seçmişlerdir. Deney sonuçlarının analiz eden araştırmacılar en düşük takım aşınmasının nano grafen katkılı MMY sistemiyle elde edildiğini iddia etmişlerdir [8]. Rahmati ve arkadaşları AL6061-T6 alüminyum alaşımını frezelerken çeşitli oranlarda bitkisel esaslı kesme sıvısının içine katılan ve 20-60 nm boyutlarındaki $\mathrm{MoS}_{2}$ nanopartikülleriyle hazırlanan nanoakışkanın, yüzey pürüzlülüğü üzerindeki etkisini incelemişlerdir. Araştırmacılar kesme sıvısı içerisine ağırlıkça \%0-0,2 0,5 ve 1 oranlarında nano $\mathrm{MoS}_{2}$ katmış ve deneyler aracılığıyla elde edilen sonuçları analiz etmişledir. Analiz sonuçlarına göre araştırmacılar, yüzey pürüzlülüğü açısından en iyi sonucun $\% 0,5$ oranında nanoakışkan ile elde edildiğini iddia etmişlerdir [9]. Sayuti ve arkadaşları sertleştirilmiş AISI 4140 çeliğini farklı katkı oranlarında sahip MMY sistemi altında işleyerek nanopartikül katkılı MMY sisteminin takım aşınması ve yüzey pürüzlülüğü üzerindeki etkisini araştırmışlardır. Katkı maddesi olarak 5-15 nm boyutlarındaki silikon dioksit $\left(\mathrm{SiO}_{2}\right)$ seçen araştırmacılar, katkı oranı olarak da ağırlıkça \%0-0,2-0,5 ve 1 oranlarını tercih etmişlerdir. Diğer değişkenler olarak ise nozul açısı $\left(15,30,45\right.$ ve $\left.60^{\circ}\right)$ ve püskürtme basıncını $(1,2,3$ ve 4 bar) seçmişlerdir. Deney sonuçlarının analizine göre optimum takım aşınmasının $\% 0,5 \mathrm{SiO}_{2}$ 
katkılı nanoakışkan, 2 bar püskürtme basıncı ve $60^{\circ}$ nozul açısı ile elde edildiğini iddia ederken optimum yüzey pürüzlülüğü değerinin ise $\% 0,5$ konsantrasyon oran1, 1 bar püskürtme basınc1 ve $30^{\circ}$ nozul açısı ile elde edildiğini iddia etmişlerdir [10]. Sharma ve arkadaşları, AISI 1040 çeliğinin işlenmesi esnasında kuru, ıslak, MQL ve nanopartikül katkılı MQL koşulları altında yüzey pürüzlülüğü, takım aşınması ve talaş morfolojisini incelemişlerdir. Konvansiyonel kesme yağının içerisine hacimce $\% 1$ oranında $45 \mathrm{~nm}$ ölçülerinde $\mathrm{Al}_{2} \mathrm{O}_{3}$ eklemişler, MQL ile yapılan her deneyde hava basıncını 4 bar, nozul açısını $30^{\circ}$ ve debiyi $50 \mathrm{ml} / \mathrm{saat}$ sabit seçmişlerdir. Deney sonuçlarına göre, nanopartikül eklenen konvansiyonel kesme yağının diğer tüm kesme koşullarına göre yüzey pürüzlülüğü, takım aşınması ve talaş morfolojisinde iyileşmeler sağladığını iddia etmişlerdir [11]. Hegab ve arkadaşları, Inconel 718 nikel esaslı süper alaşımını saf MQL, bitkisel esaslı yağın içerisine ağırlıkça $\% 2$ ve $\% 4$ gama- $\mathrm{Al}_{2} \mathrm{O}_{3}$ ve çok duvarlı karbon nanotüp (çdknt) ekleyerek sabit 5 bar basınç, $40 \mathrm{ml} / \mathrm{saat}$ debide işlemişlerdir. Yapmış oldukları çalışma sonucunda, nanopartikül katkılı MQL koşullarının, saf MQL koşuluna göre daha iyi sonuçlar verdiğini ancak en iyi sonuçların çdknt nanopartikül katkılı MQL koşulunda elde edildiğini belirtmişlerdir. Takım aşınması ve talaş morfolojisi yönünden nanopartikül katk1 oranları karşılaştırıldıklarında ise ağırlıkça \%4 çdknt katk1 oranlı MQL en iyi sonuçları verirken, gama- $\mathrm{Al}_{2} \mathrm{O}_{3}$ nanopartikül katkıların içerisinde en iyi sonuçları ağırlıkça $\% 2$ oranının verdiğini iddia etmişlerdir [12]. Hadi ve Atefi, MQL ve bitkisel esaslı kesme yağına hacimce \%1-2 gama- $\mathrm{Al}_{2} \mathrm{O}_{3}$ nanopartikül eklenen MQL kesme koşulları altında AISI D3 çeliğine, frezeleme işlemi uygulamışlar ve kesme parametrelerinin (kesme hızı, ilerleme değeri, kesme derinliği) yüzey pürüzlülüğü üzerindeki etkilerini optimize etmişlerdir. Deneylerden elde ettikleri verilerle yapmış oldukları analizler sonucunda, en iyi yüzey pürüzlülük değerine, hacimce $\% 2$ katk1lı gama- $\mathrm{Al}_{2} \mathrm{O}_{3}$ kesme koşulunda, 1500 dev/dak dönme devrinde, $0,13 \mathrm{~mm} / \mathrm{dev}$ ilerleme hızında ve 0,7 mm kesme derinliğinde elde ettiklerini iddia etmişlerdir [13].

\section{MATERYAL ve METOT}

İşlenebilirlik deneyleri, üç farklı soğutma/yağlama şartı (kuru, MMY ve NanoMMY) altında maksimum devri 10000 dev/dak, motor gücü $11 \mathrm{~kW}$ olan DELTA SEIKI CNC-1050 A marka CNC freze tezgâhında gerçekleştirilmiştir. Deney numunesi olarak kullanılan $30 \mathrm{HRc}$ sertliğindeki Waspaloy süper alaşımı, 150x100x21 mm ölçülerindedir. Deney malzemesine ait kimyasal bileşim, Tablo 1'de verilmiştir. İşleme şartlarının yanında kesme parametresi olarak kesme hızı (20, 40, 60 $\mathrm{m} / \mathrm{dak})$ ve ilerleme $(0,05-0,10$ ve $0,15 \mathrm{~mm} / \mathrm{dev})$ hızları seçilmiştir. Kesme derinliği $(0,8 \mathrm{~mm})$ ve kesme genişliği $(15 \mathrm{~mm})$ bütün deneyler boyunca sabit tutulmuştur. İşlenebilirlik deneyleri esnasında Sandvik firmas1 tarafindan üretilen R390-11 T3 08M-MM kodlu GC 2040 kalite CVD $\left(\mathrm{TiCN} / \mathrm{Al}_{2} \mathrm{O}_{3} / \mathrm{TiN}\right)$ kaplamalı karbür kesici takımlar kullanılmıştır. Takım tutucu olarak yine Sandvik firmasından temin edilen, iki ağızlı R390-025A25-11L kodlu takım tutucu tercih edilmiştir. Ayrıca, frezeleme deneyleri Taguchi'nin $\mathrm{L}_{9}$ dikey dizini kullanılarak gerçekleştirilmiştir.

Tablo 1. Deney numunesi kimyasal bileşimi.

\begin{tabular}{cccccccccc}
\hline$\% \mathrm{Al}$ & $\% \mathrm{~B}$ & $\% \mathrm{C}$ & $\% \mathrm{Cr}$ & $\% \mathrm{Co}$ & $\% \mathrm{Fe}$ & $\% \mathrm{Mo}$ & $\% \mathrm{Ni}$ & $\% \mathrm{Ti}$ & $\% \mathrm{Zr}$ \\
\hline 1,40 & 0,010 & 0,050 & 19,50 & 13,00 & 1,00 & 4,30 & 57,00 & 3,00 & 0,70 \\
\hline
\end{tabular}

MMY sistemi olarak SKF marka ve Lubrilean Vario model cihaz kullanılmıştır. Literatür bilgisi ve ön deneyler neticesinde 8 bar basınç, bitkisel kesme yağı (yoğunluk: $0,895 \mathrm{~g} / \mathrm{cm}^{3}-2{ }^{\circ} \mathrm{C}$, kinematik viskozite: $5 \mathrm{~mm}^{2} / \mathrm{sn}-40{ }^{\circ} \mathrm{C}$, parlama noktasi: $170^{\circ} \mathrm{C}$ ), $50 \mathrm{ml} / \mathrm{saat}$ debi, $30 \mathrm{~mm}$ püskürtme mesafesi ve 
45 $5^{\circ}$ püskürtme açısı MMY parametresi seçilmiştir. NanoMMY kesme şartı için ortalama 50-80 nm boyutlarındaki $\mathrm{Al}_{2} \mathrm{O}_{3}$ nanopartikülleri bitkisel esaslı kesme sıvısının içerisine hacimce \%1 oranında katılmıştır. Karışımın homojenliğini artırmak için Daihan (WiseTis HG-15D) homojenizatör kullanılmış ve böylece homojen karışım ortaya çıkarılmıştır. Homojenizatör, 2 saat süre ile 1500 dev/dak devirde çalıştırılarak homojenliğin yüksek seviyede olması sağlanmıştır.

Takım aşınmasının ölçülmesi için her deneyin bitiminden sonra talaşlar kesme bölgesinden uzaklaştırılmıştır. Her deney sonunda AM 4113ZT (Dino-Lite) polarize dijital mikroskop kullanılarak aşınma değerleri ölçülmüş ve aşınma tipi tespit edilmiştir. Her deney için daha önce kullanılmamış bir kesici uç kullanılmıştır. Deney düzeneği Şekil 1'de verilirken, Şekil 2'de ise kesici uçlara ait aşınma değerlerinin mikroskop ile ölçümü gösterilmektedir.

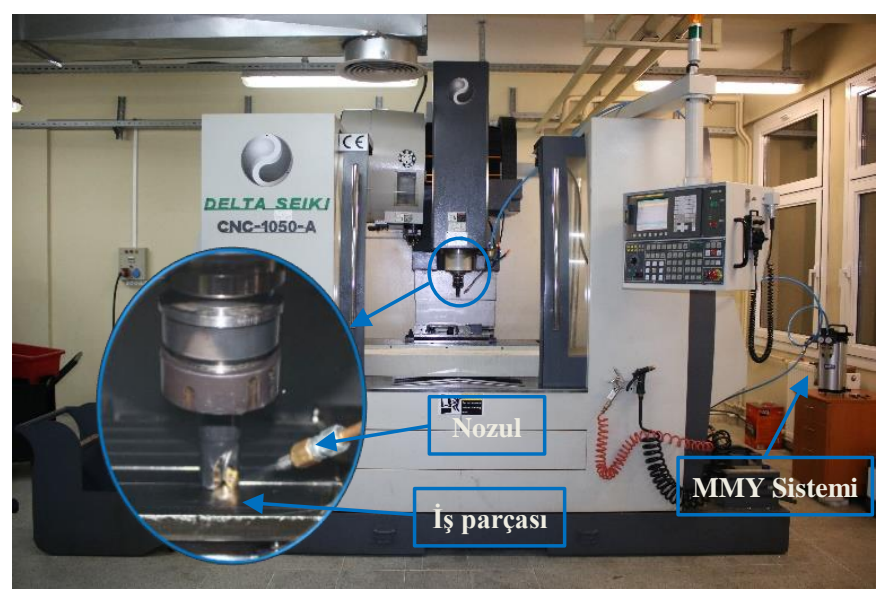

Şekil 1. Deney Düzeneği.

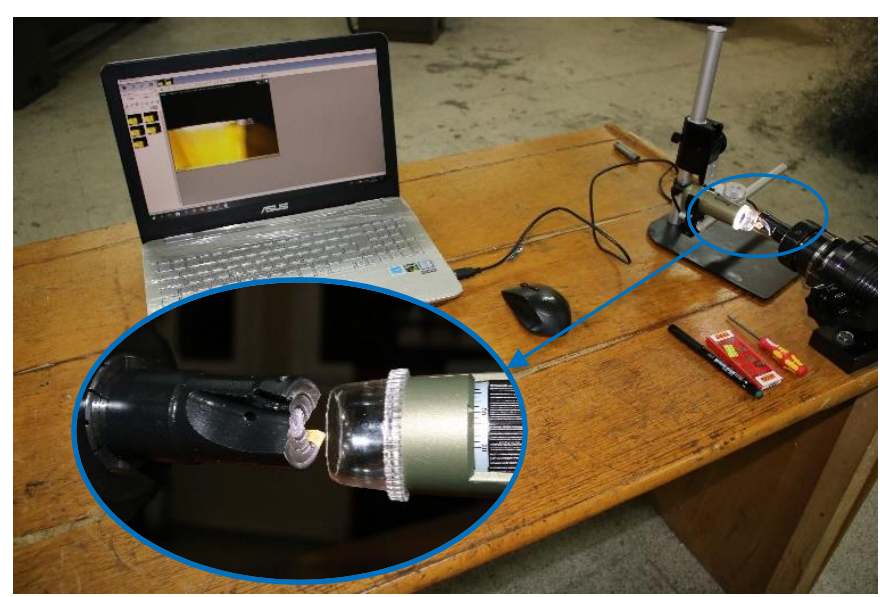

Şekil 2. Takım aşınmalarının ölçümü.

\section{SONUÇLAR VE TARTIȘMA}

\section{A. DENEYSEL SONUÇLAR}

Talaş kaldırma operasyonlarında kesme parametrelerinin etkisini belirlemek için kullanılan çıktı değerlerinin başında takım aşınması gelmektedir [11]. Bu nedenle, Waspaloy'un frezelenmesinde hem 
kesme hızı, ilerleme gibi kesme parametrelerinin hem de soğutma/yağlama yönteminin takım aşınması üzerindeki etkisini incelemek için bir dizi deney yapılmıştır. Ön deneyler esnasında dominant aşınma tipi yanak aşınması olarak belirlenmiştir ve takım ömrü kriteri ilk başta ISO 8688-1 frezeleme standardı referans alınarak, 0,3 mm'ye ulaşan takımın ömrünü tamamladığı kabul edilmiştir. Ancak bazı durumlarda $0,3 \mathrm{~mm}$ değerine çok erken ulaşıldığı için ve on-line takım aşınma değeri ölçülemediği için bu kriter değiştirilmiş ve $1612,5 \mathrm{~mm}^{3}$ sabit hacimdeki aşınma değeri alınmıştır. L9 deney tasarımı esnasında uygulanan işleme parametreleri ve bunlara karşılık gelen takım aşınma değerleri Tablo 2'de toplu olarak verilmiştir. Ayrıca, her bir parametrenin aşınma değeri üzerindeki göstermek için Minitab paket programı aracılığıyla elde edilen ortalama etki grafiği ise Şekil 3'te verilmiştir.

Tablo 2. Deney Tasarımı ve Sonuçları.

\begin{tabular}{ccccc}
\hline $\begin{array}{c}\text { Deney } \\
\text { No }\end{array}$ & $\begin{array}{c}\text { Kesme hızı } \\
(\mathbf{m} / \mathbf{d a k})\end{array}$ & $\begin{array}{c}\text { İlerleme } \\
(\mathbf{m m} / \mathbf{d e v})\end{array}$ & $\begin{array}{c}\text { Soğutma/Yağlama } \\
\text { Yöntemi }\end{array}$ & $\begin{array}{c}\text { Takım aşınması } \\
(\mathbf{m m})\end{array}$ \\
\hline $\mathbf{1}$ & 20 & 0,05 & Kuru & 0,280 \\
$\mathbf{2}$ & 20 & 0,10 & MMY & 0,202 \\
$\mathbf{3}$ & 20 & 0,15 & NanoMMY & 0,159 \\
$\mathbf{4}$ & 40 & 0,05 & MMY & 0,190 \\
$\mathbf{5}$ & 40 & 0,10 & NanoMMY & 0,190 \\
$\mathbf{6}$ & 40 & 0,15 & Kuru & 0,559 \\
$\mathbf{7}$ & 60 & 0,05 & NanoMMY & 0,332 \\
$\mathbf{8}$ & 60 & 0,10 & Kuru & 0,776 \\
$\mathbf{9}$ & 60 & 0,15 & MMY & 0,758 \\
\hline
\end{tabular}

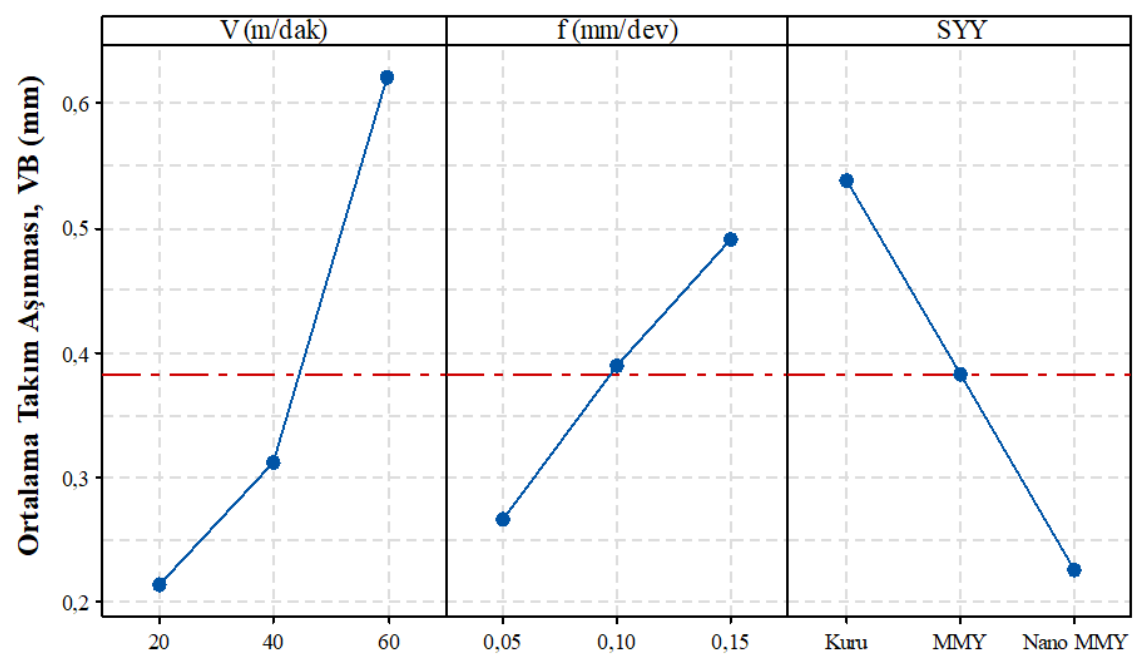

Şekil 3. İşleme parametrelerinin takım aşınması üzerindeki etkisi.

Şekil 3 incelendiğinde, kesme hızı açısından en olumlu sonucun en düşük kesme hızı değeri (20 $\mathrm{m} / \mathrm{dak}$ ) ile elde edildiği ve kesme hızının artması ile birlikte aşınma değerinin de arttığı görülmektedir. Kesme hızındaki artış, takım aşınması açısından her zaman önemli bir parametre olmuştur. Kesme hızının artması ile birlikte kesme bölgesindeki sıcaklıklar yükselmekte ve böylece kesici takım üzerindeki termal ve mekanik yükler artmaktadır. Bu da kesici takımda meydana gelen deformasyon ve bozulmaları artırmaktadır [15]. Şekil 3'te takım aşınmasının ilerlemeye bağlı olarak değişimini gösteren bölüm incelendiğinde en düşük aşınmanın en düşük ilerleme değerinde ortaya çıktığı, ilerlemenin artması ile birlikte aşınmanın da arttığı görülmektedir. Waspaloy gibi sıcak sertlik 
özelliğine sahip malzemeler işleme esnasında oluşan 1s1 ile daha da sertleşmektedir. Böylece, işlenebilirlik özellikleri daha da zorlaşmaktadır. Hem kesme hızı hem de ilerlemenin artması kesme bölgesinde oluşan 1sıyı artıracağından malzemenin işlenmesini daha da zorlaştıracaktır. Burada da böyle bir durum söz konusudur. Soğutma/yağlama yönteminin aşınmaya etkisini gösteren bölüm incelendiğinde ise en yüksek aşınmanın kuru işlemede olduğu, NanoMMY ile işlemede ise en düşük aşınma değerinin elde edildiği görülmektedir. Kesme sıvısı kullanımı ile aşınmanın azalması beklenen bir durumdur.

Şekil 4'te 1612,5 $\mathrm{mm}^{3}$ sabit hacimli talaş kaldırma operasyonu sonucu ortaya çıkan aşınma fotoğrafları verilmektedir ve kesme sıvısı kullanımı ile birlikte aşınma değerinin azaldığı bu fotoğraflarda daha net görülmektedir. Fotoğrafların sıralaması deney numarasına (Tablo 3) göre yapılmıştır. Dijital mikroskop fotoğrafları incelendiğinde aşınmanın yanak aşınması şeklinde başladığı ve daha sonra çentik aşınmasına evrildiği görülmektedir. Çentik aşınması Waspaloy gibi nikel esaslı süper alaşımlarda oldukça sık görülen ve genel karakteristik yapısı halini alan bir aşınma türüdür. Ancak düşük hızlarda ve kesme sıvısı kullanıldığı durumlarda oldukça makul seviyelere gerilemiştir. Bir başka deyişle, yüksek kesme hızları ve ilerleme değerlerinde aşınma kontrol edilemez boyuta ulaşmıştır.

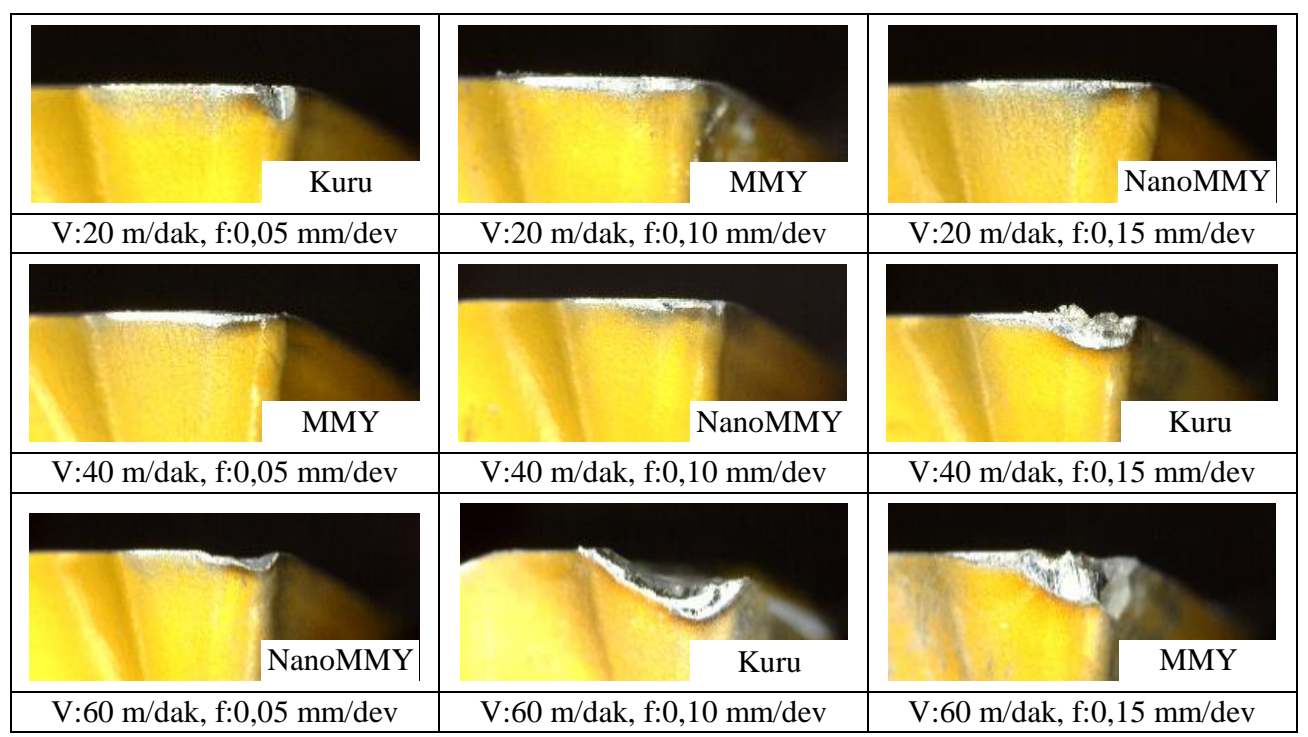

Şekil 4. Kesici takımda nihai aşınma görüntüleri (x50),

\section{B. SOĞUTMA/YAĞLAMA YÖNTEMLERININ KARŞILAŞTIRILMASI}

Deney düzeneğinin tam faktöriyel olmaması, işleme parametrelerinin bütün etkileşimlerine ait deneylerin yapılamamasına neden olmaktadır. $\mathrm{Bu}$ çalışmanın temel amacı soğutma/yağlama yöntemlerinin takım aşınması üzerindeki etkisini araştırmak olduğundan, diğer kesme parametrelerinin sabit tutulduğu ve tek değişkenin soğutma/yağlama yöntemi olduğu bir dizi deney daha yapılmıştır. Böylece soğutma/yağlama yöntemleri arasındaki farklar daha net ortaya konulmuştur. Bu deneyler esnasında orta değerler alınarak kesme hızı $40 \mathrm{~m} / \mathrm{dak}$, ilerleme ise $0,10 \mathrm{~mm} / \mathrm{dev}$ değerlerinde sabit tutulmuştur. Deneyler yine $1612,5 \mathrm{~mm}^{3}$ sabit talaş hacmi kaldırılarak yapılmıştır. Talaş derinliği de diğer deneylerle aynı olarak $0,8 \mathrm{~mm}$ şeklinde sabit tutulmuştur. Şekil 5 'te sabit kesme hızı, sabit ilerleme ve sabit kesme derinliği altında yapılan deneylere ait mikroskop görüntüleri ve kesici takım yanak aşınma değerleri verilmiştir. 


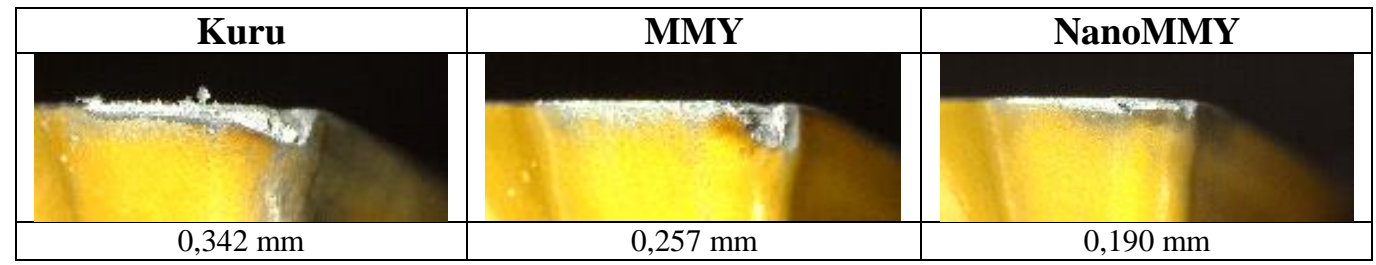

Şekil 5. Soğutmalyağlama farkını gösteren kesici uç aşınma görüntüleri (x50).

Şekil 5'te yer alan dijital mikroskop fotoğrafları incelendiğinde, en düşük aşınma değerinin NanoMMY sistemi ile elde edildiği görülürken en yüksek aşınma değerinin kuru işleme sonucunda ortaya çıktığı görülmektedir. Kuru işlemeye göre MMY sistemi \%24,9 civarında bir iyileşme sağlarken NanoMMY sistemi \%44,4 oranında bir iyileşme sağlamıştır. Kesme sıvısının takım/talaş arayüzeyine uygulanması, sürtünmeyi azalttığı için kesme bölgesinde oluşan 1sıy da düşürmekte ve böylece daha yüksek bir takım ömrüne katkı sağlamaktadır [10]. Takım aşınmasındaki bu azalma, nanopartikül katkılı kesme sıvısının takım/talaş arayüzeyine daha iyi nüfuz etmesi ve sürtünmeyi azaltmasıyla açılanabilir. Sürtünmenin azalması ise nanopartikül katkılı kesme sıvısının içinde bulunan $\mathrm{Al}_{2} \mathrm{O}_{3}$ nanopartiküllerinin bilye etkisi göstermesi ve böylece kesme s1vıs1 tarafindan oluşturulan yağ filminin daha etkili olması ile açıklanabilir [14].

\section{OPTIMIZASYON}

$\mathrm{Bu}$ çalışmada, deney tasarımı Taguchi'nin $\mathrm{L}_{9}$ dikey dizinine göre oluşturulmuştur. Taguchi yöntemi, sinyal/gürültü $(\mathrm{S} / \mathrm{N})$ analizini deney tasarımı içerisinde optimum noktaları elde etmek için kullanmaktadır. $\mathrm{S} / \mathrm{N}$ oranı, proses veya ürün tasarımını optimize etmek ve değişkenliği en aza indirmek için kullanılan logaritmik bir işlevdir. $\mathrm{S} / \mathrm{N}$ oranı, varyansın tersi olarak anlaşılabilir ve bu oranın maksimuma çıkarılması, ortamdaki istenmeyen değişikliklere karşı değişkenliğinin azaltılmasına olanak sağlamaktadır. S/N oranı analizinde, en küçük iyi, en büyük iyi ve nominal iyi şeklinde sıralanan $\mathrm{S} / \mathrm{N}$ oranı fonksiyonları bulunmaktadır ve değişkenliği en aza indirmek için, $\mathrm{S} / \mathrm{N}$ oranının en büyük değerini üreten faktör seviyesi seçilmelidir [16].

$\mathrm{Bu}$ çalı̧̧mada, analizi yapılacak olan takım aşınması deney sonuçları için minimum değeri elde etme amacı olduğundan $\mathrm{S} / \mathrm{N}$ oranlarının analizinde en küçük en iyi yaklaşımı tercih edilmiş ve hesaplamada kullanılan denklem aşağıda verilmiştir [17];

$S / N=-10 . \log \left\{\frac{1}{n} \sum_{i=1}^{n} Y^{2}\right\}$

Burada, y deneylere ait sonucu, $\mathrm{n}$ ise toplam deney sayısını göstermektedir.

Yapılan hesaplamalar neticesinde her bir faktör adına belirlenen en büyük $\mathrm{S} / \mathrm{N}$ oranı en optimum deney sonucuna denk gelmektedir. Bir başka deyişle, bütün deney sonuçları içerisinde en düşük deney sonucuna karşılık gelmektedir. Eşitlik 1 aracıllı̆ğyla hesap edilen $\mathrm{S} / \mathrm{N}$ oranları her bir faktör ve deney sonucu için Şekil 6'da grafik halinde verilmiştir. Ayrıca, Tablo 3 'te de bu grafiğin sayısal değerlerini veren $\mathrm{S} / \mathrm{N}$ yanıt tablosu verilmiştir. 


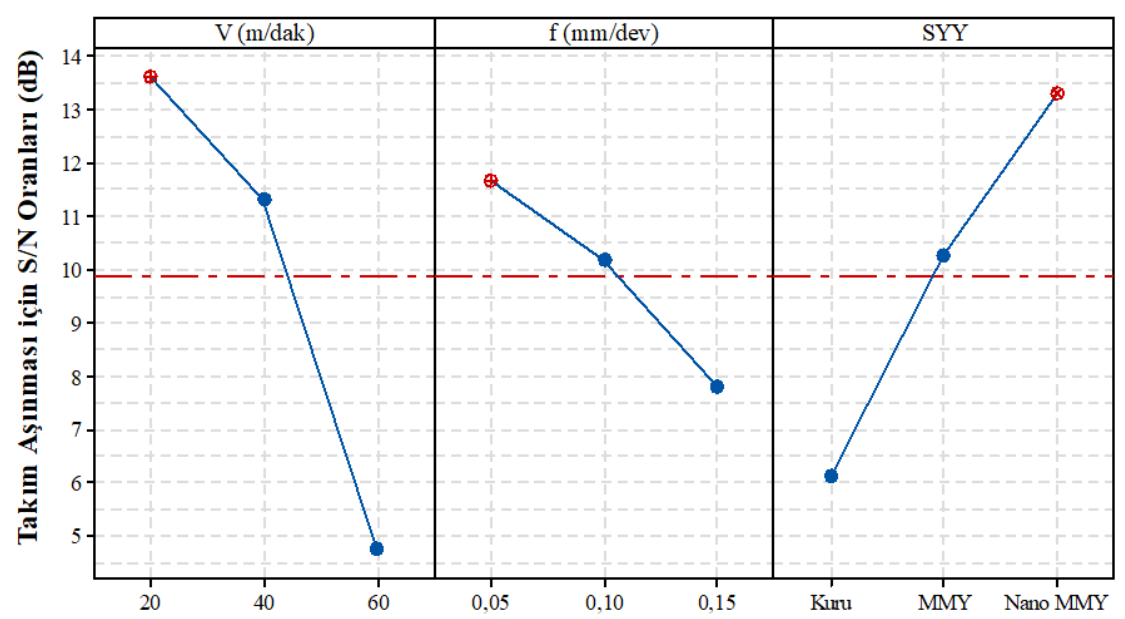

Signal-to-noise: Smaller is better

Şekil 6. Takım aşınması için S/N oranları ve optimum koşullar.

Tablo 3. S/N yanitlart tablosu.

\begin{tabular}{cccc}
\hline & \multicolumn{3}{c}{ Kontrol faktörleri } \\
\cline { 2 - 4 } Seviyeler & $\begin{array}{c}\mathrm{V} \\
(\mathrm{m} / \mathrm{dak})\end{array}$ & $\begin{array}{c}\mathrm{f} \\
(\mathrm{mm} / \mathrm{dev})\end{array}$ & $\mathrm{SYY}$ \\
\hline Seviye 1 & $\mathbf{1 3 , 6 4 1}$ & $\mathbf{1 1 , 6 8 6}$ & 6,104 \\
Seviye 2 & 11,301 & 10,174 & 10,242 \\
Seviye 3 & 4,729 & 7,810 & $\mathbf{1 3 , 3 2 5}$ \\
Delta & 8,912 & 3,876 & 7,221 \\
\hline
\end{tabular}

Şekil 6'daki grafik ve Tablo 4'teki sayısal değerlerde de görüldüğü üzere her bir faktör için S/N oranının en üst seviye olduğu noktalar o parametreye ait optimum değerleri vermektedir. Dolayısıyla, en düşük takım aşınması değerinin veren en uygun işleme parametreleri sırasıyla, kesme hızı için 1.seviye $(20 \mathrm{~m} / \mathrm{dak}, \mathrm{S} / \mathrm{N}$ oranı $=13.641 \mathrm{~dB})$, ilerleme için 1 .seviye $(0,05 \mathrm{~mm} / \mathrm{dev}, \mathrm{S} / \mathrm{N}$ oranı=11,686 $\mathrm{dB}$ ) ve soğutma/yağlama yöntemi için 3.seviye (NanoMMY, S/N oranı=13,325 dB)'dir.

\section{SONUCLLAR}

Bu çalışma ile elde edilen sonuçlar aşağıda verilmiştir;

- Waspaloy süper alaşımının farklı işleme parametreleri altında frezelenmesinde elde edilen takım aşınma değerleri faktörlerin etkileşimine bağlı olarak değişmiştir. Kesme hızının en düşük seviyesinde en uygun aşınma değeri çıkarken kesme hızının artması ile birlikte aşınma değeri de artışa geçmiştir.

- İlerleme açısından takım aşınması değerlendirildiğinde, en düşük aşınma değeri en düşük ilerleme hızında ortaya çıkmış ve ilerleme değerinin artması ile birlikte aşınma değeri de ona paralel olarak artışa geçmiştir. 
- Soğutma/yağlama yöntemlerinde en yüksek aşınma değeri kuru işlemede çıkarken en düşük aşınma değeri ise nanopartikül katkılı MMY sistemi ile işlemede çıkmıştır. Kuru işlemeye göre MMY sistemi \%24,9 civarında bir iyileşme sağlarken NanoMMY sistemi \%44,4 oranında bir iyileşme sağlamıştır. Benzer şekilde literatürde yer alan çalışmalarda, nanopartikül katkıların diğer işleme koşullarına göre farklı oranlarda (örneğin \%20 - 50) iyileşmeler sağladığı bilinmektedir [10-13].

- Takım aşınması açısından baskın aşınma türü yanak aşınması olurken aşınmanın ilerlediği durumlarda çentik aşınması da belirgin bir hal almıştır.

- $\mathrm{S} / \mathrm{N}$ oranlarının analizi ile yapılan optimizasyon neticesinde en düşük takım aşınmasını veren optimum işleme parametreleri, $20 \mathrm{~m} /$ dak kesme hızı, $0,05 \mathrm{~mm} / \mathrm{dev}$ ilerleme ve nano partikül katkılı MMY sistemi olarak bulunmuştur.

\section{KAYNAKLAR}

[1] M.M.S. Prasad and R.R. Srikant, "Performance evaluation of nano graphite inclusions in cutting fluids with MQL technique in turning of AISI 1040 steel," International Journal of Research in Engineering and Technology, vol. 2, no. 11, pp. 381-393, 2013.

[2] Ç.V. Yıldırım, T. Kıvak, M. Sarıkaya and F. Erzincanlı, "Determination of MQL parameters contributing to sustainable machining in the milling of nickel-base superalloy Waspaloy," Arabian Journal for Science and Engineering, vol. 42, no. 11, pp. 4667-4681, 2017.

[3] M. Hadad and B. Sadeghi, "Minimum quantity lubrication-MQL turning of AISI 4140 steel alloy," Journal of Cleaner Production, vol. 54, pp. 332-343, 2013.

[4] T.K. Nguyen, I. Do and P. Know, "A tribological study of vegetable oil enhanced by nanoplatelets and implication in MQL machining," International Journal of Precision Engineering and Manufacturing, vol. 13, no. 7, pp. 1077-1083, 2012.

[5] F. Klocke and G. Eisenblätter, "Dry cutting," Cirp Annals, vol. 46, no. 2, pp. 519-526, 1997.

[6] A. Uysal, F. Demiren and E. Altan, "Applying minimum quantity lubrication (MQL) method on milling of martensitic stainless steel by using nano $\mathrm{MoS}_{2}$ reinforced vegetable cutting fluid," Procedia-Social and Behavioral Sciences, vol. 195, pp. 2742-2747, 2015.

[7] K.H. Park, G.D. Yang, M.A. Suhaimi, D.Y. Lee, T.G. Kim and S.W. Lee, "The effect of cryogenic cooling and minimum quantity lubrication on end milling of titanium alloy Ti-6Al-4V," Journal of Mechanical Science and Technology, vol. 29, no. 12, pp. 5121-5126, 2015.

[8] K.H. Park, B. Ewald and P.Y. Kwon, "Effect of nano-enhanced lubricant in minimum quantity lubrication balling milling," Journal of tribology, vol. 133, no. 3, pp. 031803-031811, 2011.

[9] B. Rahmati, A.A.D. Sarhan and M. Sayuti, "Morphology of surface generated by end milling AL6061-T6 using molybdenum disulfide $\left(\mathrm{MoS}_{2}\right)$ nanolubrication in end milling machining," Journal of Cleaner Production, vol. 66, no. 1, pp. 685-691, 2014.

[10] M. Sayuti, A.A.D. Sarhan and F. Salem, "Novel uses of $\mathrm{SiO}_{2}$ nano-lubrication system in hard turning process of hardened steel AISI 4140 for less tool wear, surface roughness and oil consumption," Journal of Cleaner Production, vol. 67, no. 1, pp. 265-276, 2014. 
[11] A.K. Sharma, R.K. Singh, A.R. Dixit and A.K. Tiwari, " Characterization and experimental investigation of $\mathrm{Al}_{2} \mathrm{O}_{3}$ nanoparticle based cutting fluid in turning of AISI 1040 steel under minimum quantity lubrication (MQL)," Materials Today: Proceedings, vol. 3, no. 6, pp. 1899-1906, 2016.

[12] H. Hegab, U. Umer, M. Soliman and H.A. Kishawy, "Effects of nano-cutting fluids on tool performance and chip morphology during machining Inconel 718," The International Journal of Advanced Manufacturing Technology, vol. 96, no. 9-12, pp. 3449-3458, 2018.

[13] M. Hadi and R. Atefi, "Effect of minimum quantity lubrication with gamma- $\mathrm{Al}_{2} \mathrm{O}_{3}$ nanoparticles on surface roughness in milling AISI D3 steel," Indian Journal of Science and Technology, vol. 8, no. 3, pp. 130-135, 2015.

[14] G. Uzun ve Y. Turgut, "DIN 1.2344 ve DIN 1.2379 takım çeliklerine uygulanan dolgu kaynaklarının frezelenmesinde kesme parametrelerinin incelenmesi," 4th International Conference on Welding Technologies and Exhibition (ICWET'16), Gaziantep, Türkiye, 2016, ss. 1437-1445.

[15] T. Kivak, "Optimization of surface roughness and flank wear using the Taguchi method in milling of Hadfield steel with PVD and CVD coated inserts," Measurement, vol. 50, no. 1, pp. 19-28, 2014.

[16] J.L. Rosa, A. Robin, M.B. Silva, C.A. Baldan and M.P. Peres, "Electrodeposition of copper on titanium wires: Taguchi experimental design approach," Journal of Materials Processing Technology, vol. 209, no. 3, pp. 1181-1188, 2009.

[17] M.K. Balki, C. Sayin and M. Sarıkaya, "Optimization of the operating parameters based on Taguchi method in an SI engine used pure gasoline, ethanol and methanol," Fuel, vol. 180, no. 1, pp. 630-637, 2016. 